University of Konstanz

Department of Economics

\title{
Designing Monetary Policy Committees
}

\author{
Volker Hahn
}

Working Paper Series

2012-23

http://www.wiwi.uni-konstanz.de/forschung/ 


\title{
Designing Monetary Policy Committees*
}

\author{
Volker Hahn \\ Department of Economics \\ University of Konstanz \\ Box 143 \\ 78457 Konstanz, Germany \\ volker.hahn@uni-konstanz.de
}

First Version: March 2012

This Version: November 2012

\begin{abstract}
We integrate a monetary policy committee into a New Keynesian model to assess the consequences of the committee's institutional characteristics for welfare. First, we prove that uncertainty about the committee's future composition may be desirable. Second, we show that longer terms of central bankers lead to more effective output stabilization at the expense of higher inflation variability. Third, larger committees allow for more efficient stabilization of both output and inflation, provided that the pool of candidates is sufficiently diverse. Finally, longer terms induce the government to appoint more conservative central bankers, which is conducive to welfare.
\end{abstract}

Keywords: Monetary policy committees, term length, committee size, New Keynesian model.

JEL: $\quad$ E58, D71.

*I would like to thank Tobias Fleischer for many valuable comments and suggestions. 


\section{Introduction}

In most models of monetary policy, decisions on the monetary-policy instrument are taken by a single central banker or are described by a mechanical interest-rate rule. By contrast, in most central banks, such as the Bank of England, the Bank of Japan, the European Central Bank, the Swiss National Bank, or Sweden's Riksbank, monetary policy is determined by committee. ${ }^{1}$

What are the economic benefits and costs of monetary policy-making by committee? What are the effects of committee size and the length of committee members' terms on the performance of monetary policy? To address these questions, we introduce a monetary policy committee into an otherwise standard New Keynesian model. We focus on a particular source of heterogeneity between policy-makers: differences in preferences. ${ }^{2}$ The importance of preference heterogeneity and fluctuations in preferences for central banking has been confirmed empirically by Tootell (1999) and Meade and Sheets $(2005) .^{3}$

In the presence of stochastic preferences, monetary policy committees may be a means of insuring against policy-makers with extreme preferences, as the median voter's position in a committee is more likely to be moderate compared to the position of an individual governor. In the New Keynesian model we adopt here, an additional expectations channel is at work: In line with the New Keynesian Phillips curve, expectations about future policy-making impact on current inflation. As future policy-making is determined by the institutional framework to a significant extent, the expectations channel opens up the possibility for term length and committee size to impact on current inflation.

We derive the following results. First, we show that counter to conventional wisdom, uncertainty about future monetary policy may be beneficial. ${ }^{4}$ The underlying mechanism is that uncertainty about future monetary policy moderates inflation expectations

\footnotetext{
${ }^{1}$ Notable exceptions are Canada and New Zealand.

${ }^{2}$ As will be discussed in Section 2, dispersed information might provide further support for delegating monetary policy to a committee.

${ }^{3} \mathrm{~A}$ thorough review of the literature is given in Section 2.

${ }^{4}$ In a model of union wage setting, Sørensen (1991) was the first to argue that uncertainty may have desirable effects for the macroeconomy.
} 
and thus, in turn, current inflation. Second, we analyze the economic effects of changes in term lengths. In practice, longer terms may be advantageous due to learning on the job. Although we abstract from learning, they may be desirable in our framework, too. More specifically, we show that longer terms make for superior output stabilization. We also demonstrate that longer terms comes at the cost of higher inflation variance. Third, committee size primarily affects welfare through its effect on the variance of the median central banker's preferences. Larger committees lead to more moderate preferences of the current and future median voters. Because the performance of monetary policy depends on current policy-making as well as expectations about future monetary policy, the more moderate preferences of current and future median voters in larger committees reinforce each other and result in stable output and inflation. Finally, we extend our analysis by allowing for governments to choose central bankers optimally from a pool of potential candidates. In this extension of our framework, we identify an additional advantage of longer terms. They induce the government to pick more conservative central bankers, which is welfare-enhancing in light of the time-inconsistency problem inherent in the New Keynesian model. ${ }^{5}$

Our paper is organized as follows. We discuss the related literature in the following section. Section 3 outlines the model. We derive a general solution to our model in Section 4. In Section 5, we apply this general solution to different institutional setups. The case where governments pick candidates optimally is considered in Section 6 . Section 7 concludes.

\section{Relation to the Literature}

Our paper is related to several strands of literature. First, it is connected to the literature on committee decision-making. These papers distinguish between two different sources of heterogeneity: dispersed information and differences in preferences. If different decision-makers receive different signals, then a committee will aggregate diverse information and consequently will be superior to an individual decision maker. This fundamental insight goes back to Condorcet (1785) and has been extended to a model

\footnotetext{
${ }^{5}$ This time-inconsistency problem does not involve the classic inflation bias, but is related to the so-called stabilization bias (see Clarida et al. (1999)).
} 
of monetary policy committees by Gerlach-Kristen (2006). ${ }^{6}$ One potential disadvantage of committees will arise if information acquisition is endogenous. Free-riding incentives may lower the accuracy of information collected by decision-makers in committees and thus lead to inferior decisions (see Gerling et al. (2005) for a survey). Gersbach and Hahn (2011) show that free-riding can be avoided if decision-making is transparent, which is the case considered here.

In the present paper, we disregard information asymmetries and concentrate on differences in preferences. The importance of preference heterogeneity for the Fed's policy has been confirmed by Meade and Sheets (2005). Tootell (1999) finds that changes in policies can be traced back to changes in policy-makers' objectives. Beetsma and Jensen (1998), Sibert (2002), Gersbach and Hahn (2009), and Hahn (2009) introduce uncertainty about policy-makers preferences into models of monetary policy and examine the implications of increased transparency for welfare, among other issues.

Here we consider the central bank's communication framework as given and focus on the effect of size and term length on the performance of monetary policy. These and related institutional design questions have been addressed in neoclassical models by Sibert (2003), Mihov and Sibert (2006), Riboni (2010), and Eslava (2010). These papers assess how the design of the committee impacts on the incentives to build a reputation for avoiding the inflation bias and on the effectiveness of shock stabilization. ${ }^{7}$

In contrast to this work, we use the New Keynesian model as our workhorse. Only few papers have integrated committee decision-making into the New Keynesian paradigm. Montoro (2007) finds that interest-rate smoothing may be the outcome of a bargaining process among policy-makers when the previous period's interest rate serves as the status quo in current meetings. ${ }^{8}$ Riboni and Ruge-Murcia (2008) draw on a New Keynesian model to estimate the preferences of monetary-policy committee members

\footnotetext{
${ }^{6}$ Blinder and Morgan (2005) conduct an experiment to examine the performance and speed of decision-making in groups. The literature on monetary policy by committee has been nicely reviewed and discussed by Sibert (2006) and Blinder (2007).

${ }^{7}$ Utilizing a growth model with overlapping generations, Bullard and Waller (2004) assess the performance of different procedures to aggregate preferences in a monetary policy committee. Berentsen and Strub (2009) compare different institutional arrangements in a search model of money.

${ }^{8}$ Riboni and Ruge-Murcia (2008) do not consider an explicit model of the economy but assume an exogenous process for members' preferred decisions. Assuming that the previous period's decision serves as the default option in the current decision, they show that committees may lead to dynamic inefficiency.
} 
of the Bank of England. Both papers do not consider optimal committee design, which is our focus here. ${ }^{9}$

Finally, our paper is related to previous works that examine the appointment decision of the government. Waller (1989) takes the political business cycle literature (see Nordhaus (1975), MacRae (1977), Alesina (1987), and Rogoff and Sibert (1988)) as a starting point to develop a neoclassical model where the government can replace only one central banker in a three-member committee in each period. He analyzes the significance of central bank independence for the inflation bias and for policy uncertainty. Waller and Walsh (1996) address the question of optimal term length and Waller (2000) shows that delegation to a committee leads to policy smoothing. Our paper complements this literature by focusing on a channel that has not been considered in the papers on political business cycles as yet: The New Keynesian expectations channel. In line with this channel, expectations about future committee composition impact on current inflation.

\section{Model}

We take the canonical New Keynesian model as our starting point (see Clarida et al. (1999)). In each period $t$, the economy is described by the New Keynesian Phillips curve

$$
\pi_{t}=\delta \mathbb{E}_{t}\left[\pi_{t+1}\right]+\lambda y_{t}+\xi_{t}
$$

where $\pi_{t}$ is the $(\log )$ inflation rate, $y_{t}$ is the $(\log )$ output gap, $\delta$ is the common discount factor $(0<\delta<1)$, and $\lambda$ a positive parameter. $\mathbb{E}_{t}\left[\pi_{t+1}\right]$ denotes the rational expectations about inflation in period $t+1$. Equation (1) can be derived from microeconomic foundations, as explained in detail in Woodford (2003, ch. 3, secs. 2.1 and 2.2). The markup shocks $\xi_{t}$ are described by an $A R(1)$ process and accordingly can be written as

$$
\xi_{t}=\rho \xi_{t-1}+\varepsilon_{t}
$$

\footnotetext{
${ }^{9}$ In another paper, Riboni and Ruge-Murcia (2010) consider a backward-looking model to assess how well different voting protocols explain actual central-bank policies. Farvaque et al. (2009) examine how different decision rules impact on the volatility of policy rates.
} 
The autocorrelation coefficient $\rho$ is weakly positive and strictly smaller than one, the $\varepsilon_{t}$ 's are independent and normally distributed with zero mean and common variance $\sigma^{2}$. For completeness, we could introduce an IS curve into our model. However, this would merely complicate the analysis and would not affect our results.

The per-period social loss function, which can also be derived from microeconomic foundations (see Woodford (2003, ch. 6, sec. 2.2)), is given by

$$
l_{t}=\pi_{t}^{2}+a y_{t}^{2} .
$$

Monetary policy is conducted by a monetary policy committee. Committee members' loss functions are identical to (3), but may have a weight on the quadratic term $y_{t}^{2}$ different from $a$ (more on this later).

We extend the concept of discretionary equilibrium (see Oudiz and Sachs (1984) and Backus and Driffill (1986)) to our committee setting in the following way: In each period $t$, members vote on the preferred output gap, taking the future policy of the monetary policy committee and the public's expectations as given. ${ }^{10}$ We assume that the level of the output gap that represents the Condorcet winner is implemented. There is a unique Condorcet winner because preferences are single-peaked for quadratic loss functions. The position of a central banker with the median weight on output stabilization wins any pairwise vote on monetary policy and represents this unique Condorcet winner.

An alternative to the discretionary equilibrium is the equilibrium under commitment, which presupposes that the central bank can commit to a policy path for all future contingencies. ${ }^{11}$ We adopt the discretionary solution rather than the commitment solution for the following two reasons. First, our model involves conflicts of interest within the committee, which may impede commitment to future policies. Second, the committee composition changes over time, which makes it difficult for current central bankers to make binding commitments regarding future monetary policy, in particular due to the fact that future central bankers may pursue different objectives.

\footnotetext{
${ }^{10}$ If we introduced an IS-curve explicitly, we could make the equivalent assumption that members vote on the short-term nominal interest rate.

${ }^{11}$ See, e.g., Clarida et al. (1999) for an exposition of the equilibrium under commitment.
} 
For now, we do not specify how the median committee member's preferences evolve over time. We merely assume that the composition of the committee is described by some state $s_{t}$, which may take one out of finitely many values $\mathcal{S}=\{1, \ldots, S\}$. Its evolution is given by some Markov chain $(P, p)$ with $S \times S$ Markov transition matrix $P$ and $S$-dimensional row vector $p$ for the initial probabilities of the states. The composition of the committee is independent of the markup shock $\xi_{t}$. With slight abuse of notation, we use $a$ for the function $a: \mathcal{S} \rightarrow \mathbb{R}^{+}$that gives the median voter's weight on output stabilization as a function of the current state of the committee $s_{t}$. We write $a_{s_{t}}$ for the value of this function in state $s_{t}$.

Later, we will describe different institutional setups that will yield different matrices $P$. For now, we stay with this general specification, which will allow us to derive general expressions for the evolution of inflation and the output gap. Moreover, we will present a general expression for unconditional expected social losses.

\section{General Solution of the Model}

In this section, we describe the discretionary equilibrium of the model for a given Markov chain $(P, p)$ that describes the evolution of the committee's state $s_{t}$. The current state $s_{t}$ is commonly known in all periods $t$. The median central banker's loss function in period $t$ is

$$
l_{t}^{C B}=\pi_{t}^{2}+a_{s_{t}} y_{t}^{2}
$$

Hence, in each period $t, y_{t}$ and $\pi_{t}$ are chosen to minimize $\mathbb{E}_{t}\left[\sum_{i=0}^{\infty} \delta^{i}\left(\pi_{t+i}^{2}+a_{s_{t+i}} y_{t+i}^{2}\right)\right]$, subject to the Phillips curve (1), the shock process (2), and the Markov process for the transition of the committee state. The monetary-policy authority takes inflation expectations, the state $s_{t}$, the current shock $\xi_{t}$ and its own future policy as given.

The minimization problem in period $t$ involves the minimization of current-period losses only and leads to the condition:

$$
y_{t}=-\frac{\lambda}{a_{s_{t}}} \pi_{t}
$$

We summarize these important observations in the following lemma: 


\section{Lemma 1}

The discretionary equilibrium is given by the solution to (1), (2), and (5) for a given Markov chain $(P, p)$ for the committee state.

Equation (5) is a straightforward generalization of $y_{t}=-\frac{\lambda}{a} \pi_{t}$, which is the condition found in the literature for discretionary optimization by a policy-maker whose preferences are characterized by a constant weight on output stabilization $a$ (see, e.g., Clarida et al. (1999)). The additional complication in our model compared to standard analyses is that $a_{s_{t}}$ is not constant, but evolves in line with the stochastic process for the committee state.

Using (5) to replace the output gap in the New Keynesian Phillips curve and solving for inflation $\pi_{t}$ yields ${ }^{12}$

$$
\pi_{t}=\psi_{s_{t}}\left(\delta \mathbb{E}_{t}\left[\pi_{t+1}\right]+\xi_{t}\right)
$$

where

$$
\psi_{\sigma}:=\frac{a_{\sigma}}{a_{\sigma}+\lambda^{2}}, \quad \forall \sigma \in \mathcal{S}
$$

As will become clear, it will be useful to introduce

$$
\tilde{\psi}_{\sigma}:=\frac{\lambda}{a_{\sigma}+\lambda^{2}}, \quad \forall \sigma \in \mathcal{S} .
$$

In Appendix A, we show

\section{Proposition 1}

In a discretionary equilibrium, inflation and output in period $t$, conditional on the state being $\sigma \in \mathcal{S}$, are

$$
\begin{aligned}
& \pi_{t}=\left(\Psi(I-\delta \rho P \Psi)^{-1} E\right)_{\sigma} \xi_{t} \\
& y_{t}=-\left(\tilde{\Psi}(I-\delta \rho P \Psi)^{-1} E\right)_{\sigma} \xi_{t}
\end{aligned}
$$

where $\Psi:=\operatorname{diag}(\psi), \tilde{\Psi}:=\operatorname{diag}(\tilde{\psi}), I$ is the $S \times S$ dimensional identity matrix and $E$ is an S-dimensional column vector of ones. ${ }^{13}$

\footnotetext{
${ }^{12} \mathrm{Eq}$. (6) is formally equivalent to an asset-pricing equation, where the "price" of the asset $\pi_{t}$ is determined by the "stochastic dividend stream" $\xi_{t}$ and a stochastic discount factor $\delta \psi_{s_{t+1}}$ for valuation between dates $t$ and $t+1$.

${ }^{13}$ We use $\psi$ and $\tilde{\psi}$ to denote the $S$-dimensional column vectors with entries $\psi_{\sigma}, \sigma=1, \ldots, S$, and $\tilde{\psi}_{\sigma}, \sigma=1, \ldots, S$, respectively. Moreover, we use $\operatorname{diag}(v)$ for some vector $v$ to denote the diagonal matrix with the entries of $v$ on its diagonal.
} 
We will assume that some $n$ with $n \geq 1$ exists for which $\left(P^{n}\right)_{i j}>0 \forall i, j \in \mathcal{S}$. We will show that, for all scenarios considered in the subsequent section, such a value of $n$ actually exists. ${ }^{14}$ It is well-known (see Ljungqvist and Sargent (2004), ch. 2) that this property of $P$ implies the existence of a unique stationary distribution $p_{\infty}$ and that the probability distribution over the states $\mathcal{S}$ approaches $p_{\infty}$ asymptotically over time, independent of the initial distribution. The unique stationary distribution can be computed by solving $p_{\infty} P=p_{\infty}$.

Together with Proposition 1, these observations immediately lead to the following corollary:

\section{Corollary 1}

The unconditional variances of inflation and output are $e^{15}$

$$
\begin{aligned}
& \operatorname{Var}_{\pi}=\left(\Psi(I-\delta \rho P \Psi)^{-1} E\right)^{T} P_{\infty}\left(\Psi(I-\delta \rho P \Psi)^{-1} E\right) \cdot \frac{1}{1-\rho^{2}} \cdot \sigma^{2} \\
& \operatorname{Var}_{y}=\left(\tilde{\Psi}(I-\delta \rho P \Psi)^{-1} E\right)^{T} P_{\infty}\left(\tilde{\Psi}(I-\delta \rho P \Psi)^{-1} E\right) \cdot \frac{1}{1-\rho^{2}} \cdot \sigma^{2}
\end{aligned}
$$

where $P_{\infty}=\operatorname{diag} p_{\infty}$

In the corollary, we have used the fact that the unconditional variance of the markup shocks $\xi_{t}$ is $1 /\left(1-\rho^{2}\right) \cdot \sigma^{2}$.

In the next section, we will specify different institutional setups. Each setup will be associated with a Markov transition matrix $P$ and a corresponding set of states $\mathcal{S}$. Using Corollary 1, we will then compute unconditional per-period social losses $\operatorname{Var}_{\pi}+a \operatorname{Var}_{y}$ for the respective matrices $P$ and sets of states $\mathcal{S} .{ }^{16}$ This will enable us to study the welfare implications of different institutional setups.

\section{$5 \quad$ Institutional Setups}

In this section, the following institutional arrangements for the monetary policy committee are introduced: First, we will consider the benchmark case where the monetary

\footnotetext{
${ }^{14}$ The property will not hold in Section 6 .

${ }^{15}$ The superscript $T$ denotes the transpose of a matrix.

${ }^{16}$ Note that unconditional per-period social losses are identical to the unconditional discounted sum of social losses, up to a constant factor $1 /(1-\delta)$.
} 
policy committee's preferences are not stochastic and always conformable with society's objectives.

Second, we will examine the case of an individual decision maker with random preferences. From time to time, the individual decision maker is replaced by a new appointee from a pool of potential candidates with commonly known distribution of preferences. This simple case will enable us to gain first insights into the effects at work in our model. It can also be used to analyze the optimal term length for the case of a single decision-maker.

Third, we will generalize the previous scenario to the case of a committee comprising an arbitrary odd number of central bankers. In this scenario, we will re-examine the effects of term length and committee size on monetary policy and welfare.

Fourth, we will consider a scenario in which central bankers are appointed by the incumbent government in a two-party system. At each point in time, one party forms the government. This party can fill any vacancy on the monetary policy committee with candidates sharing its own preferences. This scenario can be used to re-assess the committee design questions addressed in the previous scenarios. It will be extended further in Section 6. There we will allow the government to make an optimal appointment decision by selecting a candidate from a large pool of potential central bankers.

\subsection{Calibration}

Before presenting numerical results for the different scenarios, we have to describe how we calibrate the basic New Keynesian model. We adopt the values selected by Clarida et al. (2000). For quarterly data, they choose $\delta=0.99, \rho=0.9$, and $\lambda=0.3$. The variance of $\varepsilon_{t}$ is not important for our findings and is thus normalized to 1 . If the social loss function is derived from microeconomic foundations, we obtain the expression $\lambda / \theta$ for the weight $a$, where $\theta$ is the elasticity of substitution in the Dixit-Stiglitz index of aggregate demand (see Woodford (2003, ch. 6, sec. 2)). The markup under monopolistic competition is $1 /(\theta-1)$ over marginal costs. Assuming a plausible markup of $10 \%$ leads to a value of $\theta=11$ and thus $a=\lambda / \theta \approx 0.03$. For the different types of central bankers, 


\begin{tabular}{|c|c|}
\hline Parameter & Value \\
\hline \hline$\delta$ & 0.99 \\
\hline$\lambda$ & 0.3 \\
\hline$\rho$ & 0.9 \\
\hline$a$ & 0.03 \\
\hline
\end{tabular}

Table 1: Parameter values

we will consider values $a_{1}=0.02$ and $a_{2}=0.0402 .{ }^{17}$ For many simulations, we will use $a=0.03$. However, because it is rather low compared to the values reported in Cecchetti and Krause (2002), which are based on observed central bank policies, we will also assume $a=0.25$ in a few cases. We summarize these parameter values in Table 1.

\subsection{Benchmark scenario}

In the benchmark scenario, the central bank minimizes social losses on a discretionary basis, i.e. in each period the central bank minimizes expected discounted social losses taking inflation expectations and its own future behavior as given. In this case, there is only one state $(S=1, \mathcal{S}=\{1\})$. We obtain $P=1, P_{\infty}=1, E=1, \Psi=a /\left(a+\lambda^{2}\right)$, and $\tilde{\Psi}=\lambda /\left(a+\lambda^{2}\right)$. As a result, Proposition 1 yields

$$
\begin{aligned}
\pi_{t} & =\frac{a}{\lambda^{2}+a(1-\delta \rho)} \xi_{t} \\
y_{t} & =-\frac{\lambda}{\lambda^{2}+a(1-\delta \rho)} \xi_{t} .
\end{aligned}
$$

These equations are identical to the ones obtained in the literature for the discretionary solution when monetary policy is chosen by an individual decision maker with society's preferences (see Clarida et al. (1999, p. 1672)).

\footnotetext{
${ }^{17}$ We introduce uncertainty about preferences in the same way as Sørensen (1991). In particular, this approach ensures that the weights of inflation and output in the loss function, normalized to sum to one, are identical in expectations to the respective values in the social loss function $(1 / 2 \cdot 1 /(1+$ $\left.a_{1}\right)+1 / 2 \cdot 1 /\left(1+a_{2}\right)=1 /(1+a)$ and $\left.1 / 2 \cdot a_{1} /\left(1+a_{1}\right)+1 / 2 \cdot a_{2} /\left(1+a_{2}\right)=a /(1+a)\right)$. In this sense, the introduction of uncertainty about central bankers' preferences leaves the average degree of conservatism of central bankers invariant.
} 
In the benchmark scenario, the expressions in Corollary 1 for the unconditional variances of inflation and output collapse to

$$
\begin{aligned}
& \operatorname{Var}_{\pi}=\left(\frac{a}{\lambda^{2}+a(1-\delta \rho)}\right)^{2} \frac{1}{1-\rho^{2}} \sigma^{2} \\
& \operatorname{Var}_{y}=\left(\frac{\lambda}{\lambda^{2}+a(1-\delta \rho)}\right)^{2} \frac{1}{1-\rho^{2}} \sigma^{2} .
\end{aligned}
$$

Unconditional social losses, which we use to assess welfare consequences, can be computed by using these expressions to evaluate $\operatorname{Var}_{\pi}+a \operatorname{Var}_{y}$. With the help of our findings for the benchmark case, we will discuss the effects of uncertainty about the central bank's preferences in the following. Subsequently, we will turn to more complex committee setups.

\subsection{The role of uncertainty about the central bank's prefer- ences}

The benchmark scenario is instructive because it can be used to illustrate the impact of uncertainty about future monetary policy-makers' preferences on current inflation. We will present a simple thought experiment that will highlight the basic mechanism underlying this relationship.

Consider the economy in a particular period $t$. Suppose, without loss of generality, ${ }^{18}$ that $\xi_{t}=1$. Monetary policy is currently in the hands of a central banker who shares society's loss function. It is commonly known that from period $t+1$ on, there is a fifty percent chance of a central banker with weight $a_{1}$ taking office and remaining in charge indefinitely. There is also a fifty percent chance of a central banker with weight $a_{2} \neq a_{1}$ holding office from period $t+1$ onward. According to (13), a type- $\sigma$ central banker with weight $a_{\sigma}(\sigma \in\{1,2\})$ will entail an inflation rate of $\pi_{t+1}=\kappa_{\sigma} \xi_{t+1}$, where

$$
\kappa_{\sigma}=\frac{a_{\sigma}}{\lambda^{2}+a_{\sigma}(1-\delta \rho)} .
$$

If the identity of the future central banker is unknown in period $t$, the public expects inflation in period $t+1$ to be $\mathbb{E}_{t}\left[\pi_{t+1}\right]=\frac{1}{2}\left(\kappa_{1}+\kappa_{2}\right) \rho$, where we have applied $\mathbb{E}_{t}\left[\xi_{t+1}\right]=\rho$.

\footnotetext{
${ }^{18}$ To be more precise, the following discussion is applicable for all $\xi_{t} \neq 0$.
} 
Moreover, set $\psi_{0}:=\frac{a}{a+\lambda^{2}}$. According to (6), the current incumbent chooses monetary policy such that

$$
\pi_{t}=\psi_{0}\left(\frac{1}{2} \delta\left(\kappa_{1}+\kappa_{2}\right) \rho+1\right)
$$

Next suppose, that the identity of the future central banker is revealed already in period $t$ before inflation expectations are formed. In this case, inflation expectations are $\mathbb{E}_{t}\left[\pi_{t+1}\right]=\kappa_{\sigma} \rho$, conditional on the future central banker being of type $\sigma \in\{1,2\}$.

If the type of the future central banker is known to be $\sigma$, we obtain

$$
\pi_{t}=\psi_{0}\left(\delta \kappa_{\sigma} \rho+1\right)
$$

It is clear from (17) and (18) that information about the future central banker's type does not affect the value of inflation $\pi_{t}$ on average. However, it introduces a meanpreserving spread, as, according to (18), inflation is high for a high value of $\kappa_{\sigma}$ and low for a low value of $\kappa_{\sigma}$. Consequently, information about the central banker's preferences in the subsequent period increases inflation variance.

As a next step, we analyze the impact of uncertainty on output variance. Recall that, according to $(5)$, output in period $t$ is directly proportional to inflation:

$$
y_{t}=-\frac{\lambda}{a} \pi_{t}
$$

This observation has the immediate consequence that uncertainty about the preferences of the central banker in $t+1$ also lowers the variance of output. As a result, irrespective of the weight on output stabilization in the social loss function, uncertainty about future monetary policy-makers' preferences is beneficial from a perspective of welfare. Our findings are a counterpoise to the widespread view that predictability of monetary policy leads to a higher degree of policy effectiveness (see, for example, Poole (2005)).

\subsection{Individual decision-maker}

In this section, we suppose that a single decision maker chooses monetary policy. While the case of an individual decision maker is less common nowadays than it was in the past (see Blinder and Morgan (2005)), the Reserve Bank of New Zealand is an example of a central bank where monetary policy is chosen by a single governor. 
For the moment, we assume that the decision maker may be of one out of two types, $\sigma=1$ or $\sigma=2$, characterized by two different weights $a_{\sigma}$ on output stabilization in his loss function. In each period $t$, the incumbent remains in office with probability $p$ $(0<p<1)$. With probability $1-p$, the incumbent central banker is replaced by a new candidate, who is of either type $\sigma \in\{1,2\}$ with equal probability. The preferences of the central banker who is in office are always commonly known.

These assumptions imply the transition matrix

$$
P=\left(\begin{array}{cc}
\frac{1}{2}(1+p) & \frac{1}{2}(1-p) \\
\frac{1}{2}(1-p) & \frac{1}{2}(1+p)
\end{array}\right)
$$

The entries on the diagonal, $1 / 2 \cdot(1+p)$ result from the observation that the probability of the incumbent remaining in office is $p$ and that the probability of the incumbent being replaced by a new candidate of identical type is $1 / 2 \cdot(1-p)$. These terms sum to $1 / 2 \cdot(1+p)$. The off-diagonal entries can be obtained by noting that the entries in both rows have to sum to one.

The unique stationary distribution is given by the row vector $p_{\infty}=(1 / 2,1 / 2)$. Moreover, we obtain the following expressions for $\Psi=\operatorname{diag}(\psi)$ and $\tilde{\Psi}=\operatorname{diag}(\tilde{\psi})$ :

$$
\begin{aligned}
\Psi & =\left(\begin{array}{cc}
\frac{a_{1}}{\lambda^{2}+a_{1}} & 0 \\
0 & \frac{a_{2}}{\lambda^{2}+a_{2}}
\end{array}\right), \\
\tilde{\Psi} & =\left(\begin{array}{cc}
\frac{\lambda}{\lambda^{2}+a_{1}} & 0 \\
0 & \frac{\lambda}{\lambda^{2}+a_{2}}
\end{array}\right),
\end{aligned}
$$

where we have applied definitions (7) and (8). Armed with these expressions and taking into account $E=(1,1)^{T}$, we can use Corollary 1 to compute welfare.

After these preparations, we examine how strongly current inflation $\pi_{t}$ and output $y_{t}$ are affected by the current markup shock $\xi_{t}$. For this purpose, we display coefficients $\left(\Psi(I-\delta \rho P \Psi)^{-1} E\right)_{\sigma}$ and $\left(\tilde{\Psi}(I-\delta \rho P \Psi)^{-1} E\right)_{\sigma}$ from Proposition 1 in the two possible committee states $\sigma \in\{1,2\}$ as functions of the central banker's term length. ${ }^{19}$ In Figure 1, the solid lines show the coefficients in state $\sigma=1$, in which the central banker attaches weight $a_{1}=0.02$ to output stabilization. The broken lines display the values of the coefficients in state $\sigma=2$, in which the central banker's current weight on output is $a_{2}=0.0402$.

\footnotetext{
${ }^{19}$ The expected term length (in quarters) can be readily computed as $\sum_{i=1}^{\infty} i p^{i-1}(1-p)=\frac{1}{1-p}$. In the figures we report term length in years. Accordingly, we divide this expression by 4 .
} 

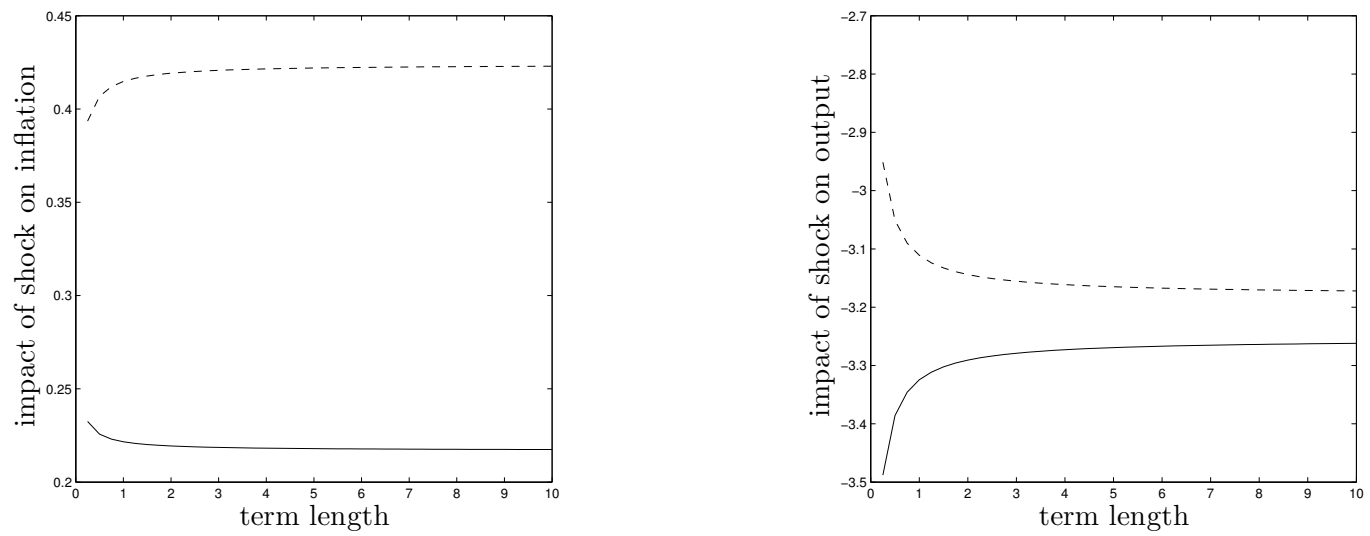

Figure 1: Individual decision-maker: coefficients $\left(\Psi(I-\delta \rho P \Psi)^{-1} E\right)_{\sigma}$ (left) and $(\tilde{\Psi}(I-$ $\left.\delta \rho P \Psi)^{-1} E\right)_{\sigma}$ (right) as functions of expected term length in years for $\sigma=1$ (solid line) and $\sigma=2$ (broken line). Parameters: $\delta=0.99, \rho=0.9, \lambda=0.3$, and $a_{1}=0.02$ and $a_{2}=0.0402$

In state $\sigma=1$, the central banker is more conservative in the sense that he cares less about output than a type-2 central banker $\left(a_{1}<a_{2}\right)$. It is therefore plausible that markup shocks have a stronger impact on inflation in state $\sigma=2$ than in state $\sigma=1$. This can be verified by observing that the broken line on the left-hand side of Figure 1 is farther away from the zero line (which is not displayed) than the solid line. On the other hand, a conservative central banker allows for a stronger impact of markup shocks on output. As a consequence, the values on the solid line on the right-hand side of Figure 1 are farther away from zero than those on the broken line.

The coefficients displayed in Figure 1 do not only depend on the current state of the committee but are affected by the central banker's term length in addition. This is a consequence of the New Keynesian Phillips curve (1), according to which inflation depends on expected future inflation and thus also on the expected preferences of the future policy-maker.

Suppose $\sigma=1$ and, accordingly, that the central banker is conservative (recall that $a_{1}<a_{2}$ ). If terms are very long, the public expects the conservative central banker to remain in office for a long time and hence that inflation will be close to its target in the future. As a result, current expectations about future inflation are close to the inflation target despite the persistence in markup shocks. This, in turn, implies that current markup shocks have only a moderate effect on current inflation. 

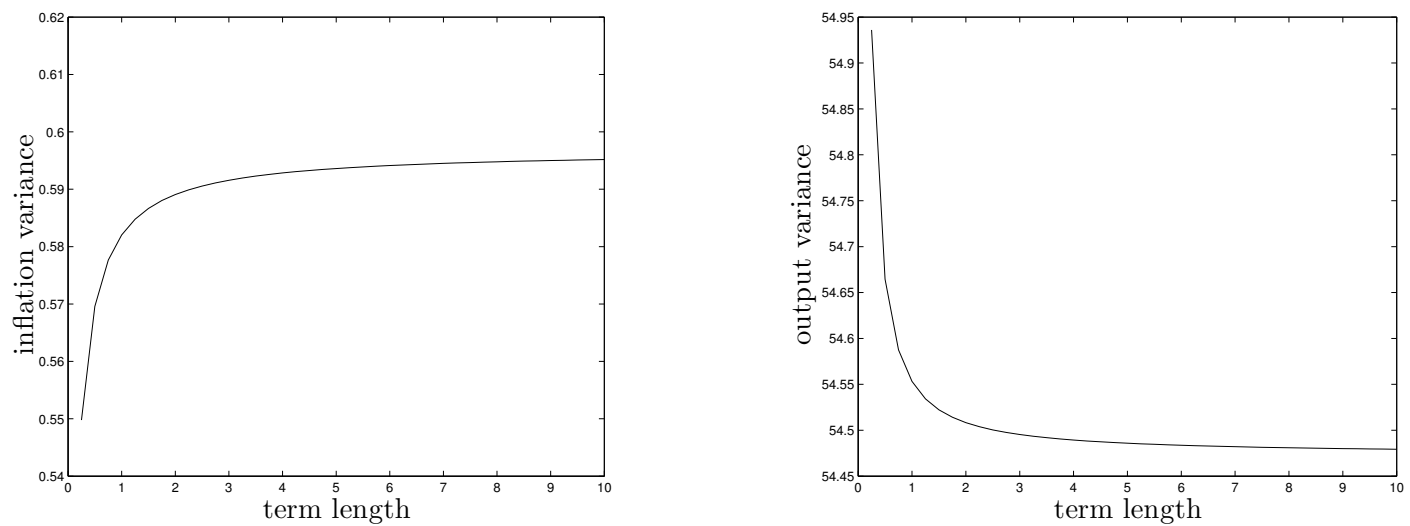

Figure 2: Individual decision-maker: unconditional variances of inflation and output as a function of expected term length in years. Parameters: $\delta=0.99, \rho=0.9, \lambda=0.3$, and $a_{1}=0.02$ and $a_{2}=0.0402$

If terms are very short, it is well possible that a less conservative central banker will hold office in the near future. As a consequence, inflation expectations will be farther away from zero, which causes the impact of current markup shocks on current inflation to be stronger than in the case where terms are long. This line of reasoning explains why the solid line on the left-hand side in Figure 1 decreases monotonically. The shape of the broken line in the same diagram has an analogous interpretation.

To understand the right-hand side of Figure 1, which shows the coefficients describing how strongly markup shocks affect output $\left(\tilde{\Psi}(I-\delta \rho P \Psi)^{-1} E\right)_{\sigma}$, we focus again on the case of $\sigma=1$ or a conservative office-holder. First, if terms are short, inflation expectations will be comparably far away from the socially optimal level of inflation, i.e. zero. Because the current office-holder is conservative, he nevertheless attempts to stabilize inflation strongly, which leads to large values of the current output gap. Second, under long terms, a conservative central banker faces a more benign tradeoff between inflation and output stabilization: Because inflation expectations are close to zero, he has to incur only moderate deviations of the output gap from zero to stabilize current inflation. This line of reasoning explains why the solid line on the right in Figure 1 increases monotonically.

Because we are interested in the optimal design of committees, we plot the unconditional variances of inflation and output in Figure 2. Jointly, both variances determine 
unconditional social losses. Figure 2 reveals that inflation variance increases monotonically with term length. This can be explained by re-considering the graphs displayed on the left-hand side of Figure 1. If terms are long, then the impact of markup shocks on inflation will be either very high in the case of a type-2 office-holder or very low in the case of a central banker of type 1. This leads to a comparably high unconditional variance of inflation. By contrast, short terms dampen the otherwise strong response of inflation to markup shocks under type-2 central bankers. As a result, the unconditional variance of inflation increases monotonically with term length. An analogous line of reasoning can be used to explain why output variance decreases with term length.

What is the optimal term length in this scenario? This depends on how strongly society values output stabilization. If $a$ in the social loss function is high, society will benefit from the low variance of output under long terms. By contrast, long terms will be harmful to society if it puts high emphasis on inflation stabilization. For $a=0.03$, which is the value indicated by the derivation of the social loss function from microeconomic foundations (see Section 5.1), our numerical computations show that the optimal term length would be as short as possible and thus only one quarter. However, we will see that this finding can be overturned when we take additional effects into account.

\subsection{Committee of arbitrary size}

The next scenario is a straightforward generalization of the case considered in the previous section: Monetary policy is not chosen by an individual decision-maker but by a committee comprising $N(N \geq 1)$ decision-makers. Each central banker may be of one of two types, either having a weight $a_{1}$ or a weight $a_{2}$ on output stabilization in his loss function. At the beginning of each period, each central banker remains in office with probability $p$; he is replaced by a new candidate otherwise. The new candidate is of either type with equal probability. All events of central bankers being replaced are independent. We assume again that, at all times, the current composition of the committee is commonly known. In each period, the policy preferred by a majority of central bankers is adopted. For simplicity, we assume that $N$ is odd. This is not essential but obviates the need to specify a tie-breaking rule to resolve draws. 


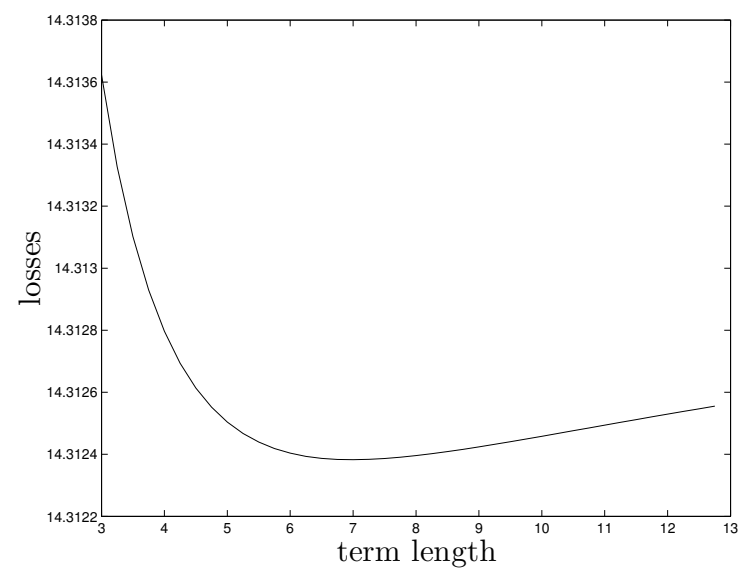

Figure 3: Three-member committee: unconditional losses as a function of expected term length in years. Parameters: $N=3, \delta=0.99, \rho=0.9, \lambda=0.3, a_{1}=0.02$, $a_{2}=0.05$, and $a=0.25$

For a committee of size $N$, there are $S=N+1$ different states because the committee may comprise $n=0,1, . ., N$ members of type 1 (and $N, N-1, \ldots, 1,0$ members of the second type accordingly). In Appendix B, we state the matrices necessary to evaluate (9)-(12).

The scenario with $N$ committee members can be used to demonstrate that the finding from the previous section that terms should be as short as possible does not hold in general. In Figure 3, we display social losses for a three-member committee as a function of term length. We choose $a_{1}=0.02, a_{2}=0.05$, and a larger value of $a$, $a=0.25$, which is compatible with Cecchetti and Krause (2002). In this case, social losses have a minimum at a term length of roughly 7 years. So our model is rich enough to yield interior solutions for the optimal term length of central bankers. ${ }^{20}$

As a next step, we consider the issue of optimal committee size for the same calibration as in the previous paragraph. We assume that the expected term length amounts to five years, which appears to be a plausible value. For example, the president of the Federal Reserve is appointed for five years. ${ }^{21}$ Figure 4 reveals that larger committees are better than smaller ones. This provides a new rationale for monetary policy-making

\footnotetext{
${ }^{20}$ There are also calibrations that result in an optimal committee size that is finite and larger than one.

${ }^{21}$ The Fed's president may serve for more than one term. This is consistent with our model because a central banker may be replaced by a committee member with identical preferences, which is equivalent to re-appointment.
} 


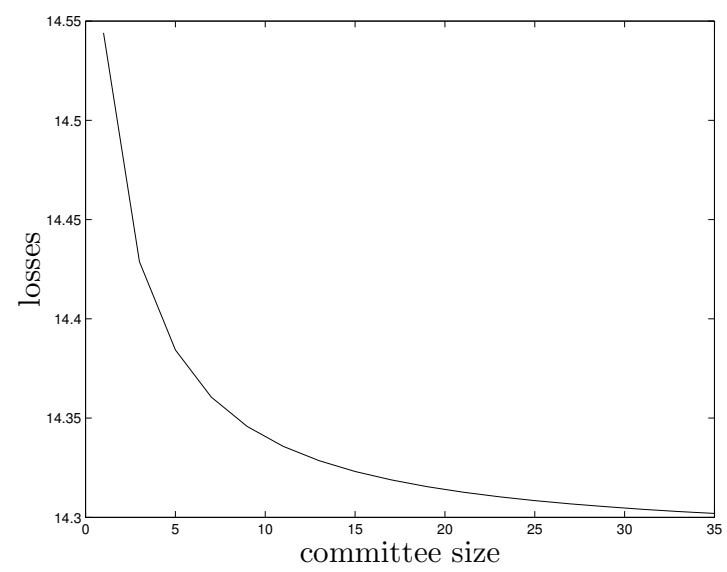

Figure 4: N-member committee: unconditional losses as a function of committee size. Parameters: $p=0.95$ (term length: 5 years), $\delta=0.99, \rho=0.9, \lambda=0.3, a_{1}=0.02$, $a_{2}=0.05$, and $a=0.25$

by committee, supporting earlier findings in the literature (see Waller (2000), Blinder and Morgan (2005), and Gerlach-Kristen (2006)).

For completeness, we display the variances of output and inflation when the value of $a$ is based on structural parameters (see Section 5.1). These variances are provided as surface plots in Figure 5. The figures reveal that committee size has only a negligible effect on the variances of inflation and output and thus on social welfare. Far more important are the committee members' term lengths, with longer terms leading to a higher variance of inflation, but a lower variance of output. Hence, our results about the impact of term length confirm our previous findings obtained for an individual decision-maker in the benchmark calibration.

By focusing on two possible realizations of committee members' preferences, we have abstracted so far from the important effect that committees may insure society against the possibility of individual central bankers with extreme preferences determining monetary policy. The simplest variant of our model in which this effect can be analyzed is one with three different types of central bankers, where each new appointee has equal probability of being of one of these types. The respective results are presented in Figure 6 for $a_{1}=0.02, a_{2}=0.03$, and $a_{3}=0.0402$.

The figure reveals that, the larger the committee, the lower are the variances of inflation and output. Consequently, larger committees raise social welfare unambiguously. Note 

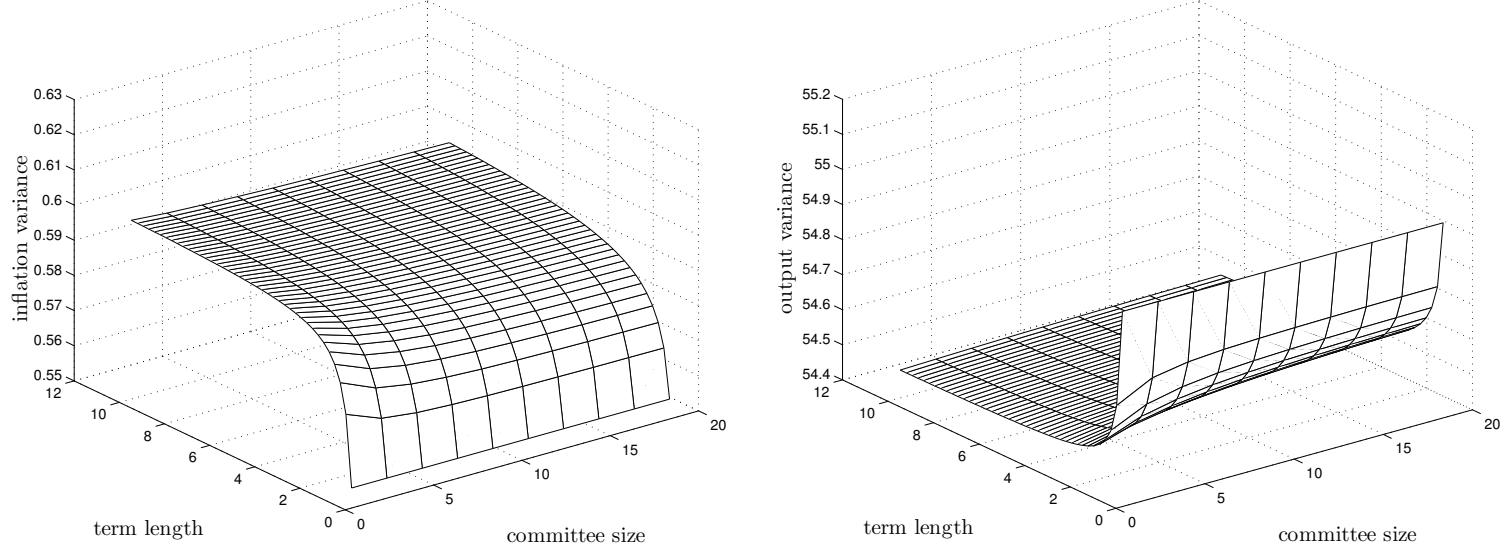

Figure 5: N-member committee: unconditional variances of inflation and output as a function of committee size and term length (in years). Parameters: $\delta=0.99, \rho=0.9$, $\lambda=0.3, a_{1}=0.02, a_{2}=0.0402$, and $a=0.03$

that this effect is not only due to the more moderate preferences of current median central bankers in large committees compared to smaller ones. It is also driven by the fact that future median voters are expected to have moderate preferences in large committees. The latter effect leads to lower fluctuations in inflation expectations and thus to a more benign tradeoff between output and inflation for current policy-makers.

\subsection{Government-appointed committee members}

In the previous scenario, we have considered a committee of $N$ ( $N$ odd) central bankers and assumed that each vacancy is filled with a candidate with random preferences. In particular, each new central banker was of one out of two types with equal probabilities. This approach did not take into account the fact that, in most countries, central bankers are appointed by elected politicians. This case is considered now.

We assume that there are two different parties, characterized by two different possible weights $a_{1}$ and $a_{2}$ in their objective functions. At the beginning of each period, there is a constant probability $q(0<q<1)$ of the government remaining in office. With the complementary probability $1-q$, the government is not re-elected and the other party forms the government. The current government fills all vacancies on the committee with candidates sharing its own preferences. Each seat on the committee becomes vacant with probability $1-p$, the incumbent member continues to hold office with probability $p(0<p<1)$. 

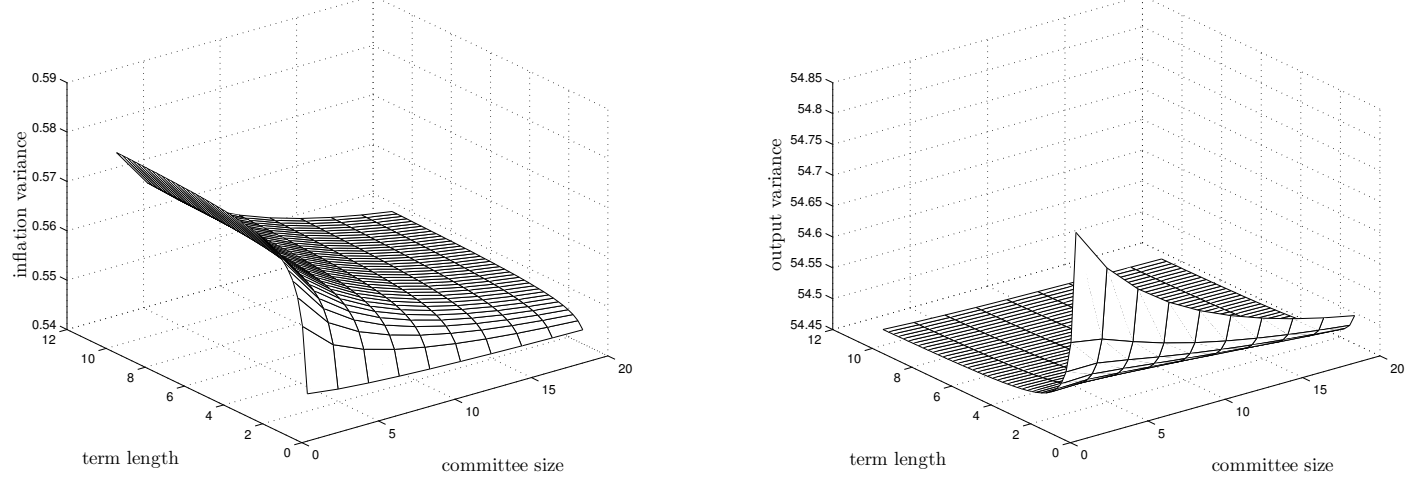

Figure 6: N-member committee, three central-banker types: unconditional variances of inflation and output as a function of committee size and term length (in years). Parameters: $\delta=0.99, \rho=0.9, \lambda=0.3, a_{1}=0.02, a_{2}=0.03, a_{3}=0.0402$ and $a=0.03$.

To compute the results for this variant of our model, we have to choose a value for the expected number of consecutive periods that the incumbent party forms the government. For this purpose, we note that the government is elected for four years in many democracies. The empirical literature usually finds an incumbency advantage (see, e.g., Carey et al. (2000), Cox and Katz (1996), and Erikson (1971)). In line with these observations, we assume that the incumbent government is re-elected with a $55 \%$ probability, which implies that the expected time during which the government type does not change is $1 /(1-0.55) \times 4 \approx 8.9$ years. A government with probability 0.9719 of surviving each quarter holds office roughly for the same expected time. Consequently, we set $q$ to this value. ${ }^{22}$

In Figure 7, we plot coefficients $\left(\Psi(I-\delta \rho P \Psi)^{-1} E\right)_{\sigma}$, which give the responsiveness of inflation to markup shocks, for a committee comprising thirteen members. On the left hand, we plot the coefficients for short terms of central bankers (1 year). Term length amounts to 5 years on the right hand. We display the number of type- 1 central bankers on the horizontal axis. Solid lines stand for a current government of type 1 and broken ones for one of type 2 .

Several observations are noteworthy. First, the coefficients decrease monotonically in the number of type- 1 central bankers. This is plausible because type- 1 central bankers

\footnotetext{
${ }^{22}$ We have confirmed that our findings are not sensitive to the particular value of $q$.
} 

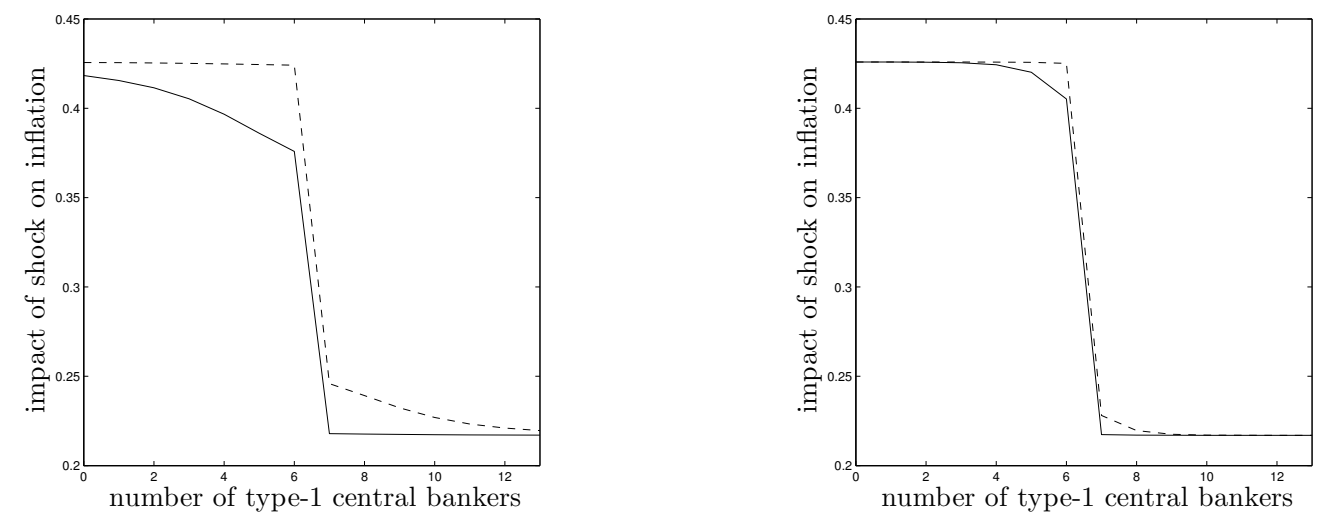

Figure 7: Government appointed committees: impact of markup shock on inflation, conditional on the incumbent government being of type 1 with $a_{1}=0.02$ (solid lines) or type 2 with $a_{2}=0.0402$ (broken lines). The number of type- 1 central bankers is displayed on the horizontal axis. Left side: central bankers' term is 1 year. Right side: 5 years. Other parameters: $\delta=0.99, \rho=0.9$, and $\lambda=0.3$. Government holds office for 8.9 years on average.

are more conservative and thus stabilize inflation more strongly. Second, all lines display a jump between 6 and 7 , which is a consequence of the observation that at this point the majority in favor of a particular policy changes in a committee consisting of thirteen members. Third, the jump is smaller for short term lengths, i.e. on the lefthand side, because in this case a narrow majority for type 2 , for example, is unlikely to persist, conditional on the government being of type 1 .

The third observation explains why inflation variance is a monotonically increasing function of central bankers' term lengths (see Figure 8). Moreover, Figure 8 shows that our previous finding that longer terms lower the variance of output extends to the scenario of government-appointed central bankers.

\section{Optimal delegation}

It is well-known that delegation to a conservative central banker may be welfare enhancing in the New Keynesian model even when the classic inflation bias plays no role (see Clarida et al. (1999)). Starting from this observation, we take our analysis of the previous section to the next level and examine the optimal appointment of central 

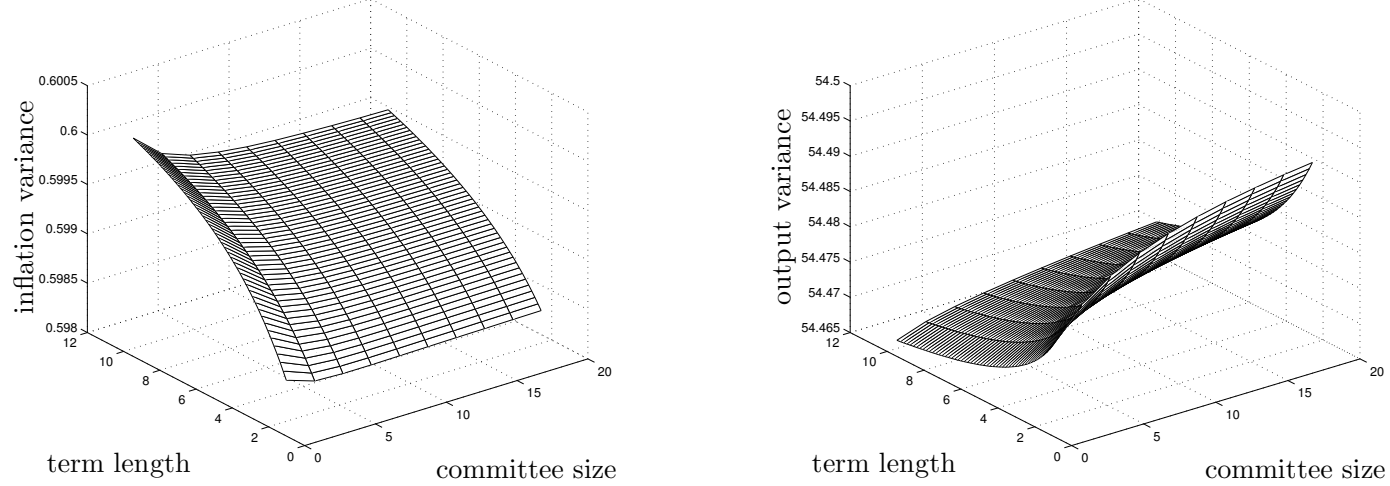

Figure 8: Government appointed committees: unconditional variances of inflation and output as a function of committee size and term length (in years). Parameters: $\delta=$ 0.99, $\rho=0.9, \lambda=0.3, a_{1}=0.02, a_{2}=0.0402$, and $a=0.03$. Government holds office for 8.9 years on average.

bankers by the current government. In particular, we focus on how the government's appointment decision is influenced by term length.

We assume that monetary policy is conducted by an individual central banker and that the government's preferences are identical to those of society. These preferences are characterized by a constant weight on output fluctuations, $b$. If the position as governor of the central bank becomes vacant in a particular period (which occurs with probability $1-p$ ), the government will be able to appoint a central banker from a large pool of candidates with values of $a$ on the interval $[0, \infty]$.

To analyze this optimization problem in a particular period in which the government has the opportunity to replace the central banker, we have to distinguish between two different states that can occur in future periods. First, the central banker appointed in the period under consideration, characterized by $a_{1}$, may still be in charge. We label this state $\sigma=1$. Second, the central banker may have been replaced by someone else. We refer to this case as state $\sigma=2$. The new central banker will have weight $a_{2}$, which is the value the government will find optimal in the future. ${ }^{23}$ This value of $a_{2}$ is taken as given by the current government.

\footnotetext{
${ }^{23}$ Note that, for the moment, we assume that the government's choice of central banker is unaffected by $\xi_{t}$. Later, we will see that this is actually consistent with the government minimizing its loss function.
} 
The transition probabilities between the two states are given by the matrix ${ }^{24}$

$$
P=\left(\begin{array}{cc}
\theta & 1-\theta \\
0 & 1
\end{array}\right) \text {. }
$$

Consider the following mapping, which describes the government's optimal choice of $a_{1}$ as a function of its own future choice $a_{2}$ :

$$
\begin{aligned}
& a_{1}\left(a_{2}\right)=\operatorname{argmax}_{a_{1}}\left\{\mathbb{E}_{t}\left[\sum_{\tau=0}^{\infty} \delta^{\tau}\left(\pi_{t+\tau}^{2}+b y_{t+\tau}^{2}\right)\right]\right\} \\
& \text { subject to (2), ( } 7)-(10),(20), \\
& \text { the current state } \sigma=1 \text {, and } a_{2} \text { and } \xi_{t} \text { given } \text {. }
\end{aligned}
$$

With this mapping, we are in a position to define a discretionary equilibrium with optimal delegation:

\section{Definition 1}

A discretionary equilibrium with optimal delegation is a fixed point $a^{*}$ of mapping (21).

In Appendix D, we show

\section{Lemma 2}

The unique fixed point of mapping (21) is

$$
a^{*}=(1-\rho \theta \delta) b \text {. }
$$

Hence, we obtain a simple relationship between $a^{*}$, the central banker's weight on output stabilization as chosen by the government, and $\theta$, which is the probability of the central banker remaining in office in a particular period: The higher this probability is, the more conservative the central banker chosen by the government will be. Before explaining this finding, we display social losses as a function of expected term length (see Figure 9).

Our results have the following interpretation. The New Keynesian model features a well-known time-inconsistency problem: The central bank would find it optimal at a given point in time to commit to stabilizing inflation strongly in the future, thereby stabilizing also current inflation via the New Keynesian Phillips curve. However, with a

\footnotetext{
${ }^{24}$ Obviously, $\sigma=2$ is an absorbing state. As a result, the assumption utilized in previous sections, namely that $n$ with $n \geq 1$ exists for which $P_{i j}^{n}>0 \forall i, j \in \mathcal{S}$, does not hold.
} 


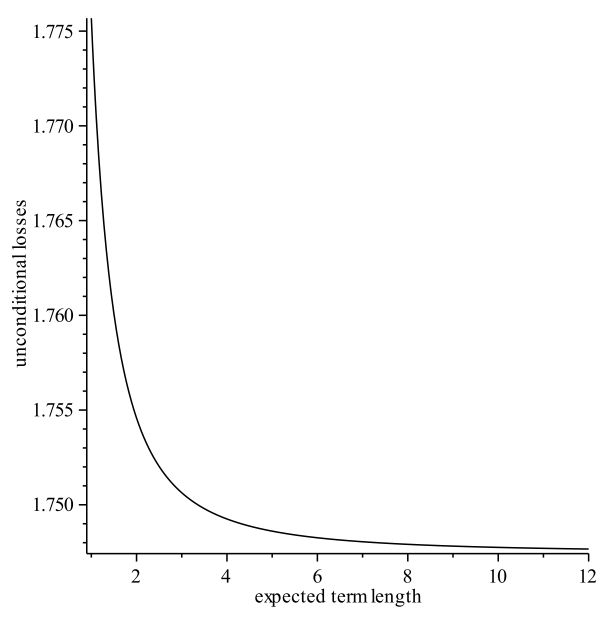

Figure 9: Unconditional per-period social losses as a function of the central banker's expected term length in years. Parameters: $\delta=0.99, \rho=0.9, \lambda=0.3$, and $b=0.03$

commitment technology wanting, the central bank will not find this behavior optimal later. A conservative central banker creates welfare gains because the public knows that he will attempt to keep inflation close to its target in the future.

In the framework considered in this section, this time-inconsistency problem is shifted one level upwards: The government would benefit from the ability to make a credible promise that a conservative central banker will be in charge in the future, because this would stabilize inflation expectations. Long terms for central bankers are a means of achieving such commitment and are thus welfare-enhancing. ${ }^{25}$

It is instructive to consider the polar case with $\theta=0$. In this case, the central banker is replaced every period. The government cannot overcome the time-inconsistency problem, as it cannot credibly promise to select conservative central bankers in the future. Accordingly, the government appoints central bankers that share its weighting of objectives in the loss function $\left(a^{*}=b\right)$.

This result is related to McCallum (1995). He pointed out that attempts to avoid the time-inconsistency problem of monetary policy merely relocate this problem from the central bank to the government. This observation holds for very short terms in our model. If, however, terms are long and there are effective institutional safeguards that

\footnotetext{
${ }^{25}$ One can interpret $\theta \delta$ as an effective discount factor in (22). A high value of $\theta$ makes the government focus more on the long run and thus pick a conservative central banker. Conversely, low values of $\theta$, which entail that the central banker will leave shortly, make the government more short-sighted.
} 
restrain the government from dismissing central bankers before the end of terms, then the time-inconsistency problem can be alleviated.

\section{Conclusions}

Our model has provided us with several insights about the consequences different characteristics of monetary policy committees have for welfare. We have demonstrated that the institutional parameters of the central bank's decision-making body impact on the outcomes of monetary policy not only through their effect on the current composition of the central bank's decision-making body. They influence expectations of future monetary policy in addition, which in turn affect current inflation.

This expectations channel may make uncertainty about the future composition of the monetary policy committee desirable, as uncertainty about the monetary policy stance in the future moderates inflation expectations. Moreover, longer terms for central bankers involve a tradeoff: They lead to more effective output stabilization at the expense of higher inflation variability. An important advantage of longer terms arises when we endogenize the government's appointment decision. Longer terms lead to the appointment of more conservative central bankers. Thus long terms serve as a commitment device that helps to reduce the stabilization bias and thereby ameliorates welfare.

In most scenarios we have considered, committee size has a minor impact on the performance of monetary policy. The most significant benefit of larger committees in our model stems from preventing policy-makers with extreme preferences to influence monetary policy. This makes extreme policies both in the current and in future periods less likely and hence yields a reduction in inflation variance.

There are other potentially relevant extensions to our model. First, if learning on the job was important, the optimal term length would be higher. Second, we have abstained from considering heterogeneous information. If information could not be aggregated effectively by consultations between a governor and the staff, then decision-making by committee would involve additional benefits. Third, if we introduced imperfect information about current central banker's preferences, the incentives for reputation 
building could be studied in our model for different committee designs. ${ }^{26}$ Examining the incentives for reputation-building in a New Keynesian model would be an interesting avenue for future research.

\footnotetext{
${ }^{26}$ So far, these incentives have only been considered in neoclassical models, as detailed in Section 2.
} 


\section{A Derivation of Expressions for Inflation and the Output Gap}

For convenience, we repeat (6):

$$
\pi_{t}=\psi_{s t}\left(\delta \mathbb{E}_{t}\left[\pi_{t+1}\right]+\xi_{t}\right)
$$

Iterating forward yields

$$
\pi_{t}=\mathbb{E}_{t}\left[\sum_{t^{\prime}=0}^{\infty} \delta^{t^{\prime}}\left(\prod_{i=0}^{t^{\prime}} \psi_{s_{t+i}}\right) \xi_{t+t^{\prime}}\right]
$$

With the help of $\mathbb{E}_{t}\left[\xi_{t^{\prime}+t}\right]=\rho^{t^{\prime}} \xi_{t}$, this can be formulated as

$$
\begin{aligned}
\pi_{t} & =\mathbb{E}_{t}\left[\sum_{t^{\prime}=0}^{\infty}(\delta \rho)^{t^{\prime}}\left(\prod_{i=0}^{t^{\prime}} \psi_{s_{t+i}}\right)\right] \xi_{t} \\
& =\psi_{s_{t}} \mathbb{E}_{t}\left[\sum_{t^{\prime}=0}^{\infty}\left(\prod_{i=1}^{t^{\prime}} \delta \rho \psi_{s_{t+i}}\right)\right] \xi_{t}
\end{aligned}
$$

where we use the convention $\prod_{i=1}^{0} \delta \rho \psi_{s_{t+i}}=1$. We note that

$$
\mathbb{E}_{t}\left[\psi_{s t}\left(\prod_{i=1}^{t^{\prime}} \delta \rho \psi_{s_{t+i}}\right)\right]=\left(\Psi(\delta \rho P \Psi)^{t^{\prime}} E\right)_{s_{t}} \quad \forall t^{\prime} \geq 0
$$

where the superscript $s_{t}$ on the right-hand side denotes the $s_{t}$-th component of the $S$ dimensional vector $\Psi(\delta \rho P \Psi)^{t^{\prime}} E$ and $\Psi$ and $E$ are defined in Proposition $1 .{ }^{27}$ Inserting (24) into (23) yields the following expression for inflation

$$
\begin{aligned}
\pi_{t} & =\left(\sum_{t^{\prime}=0}^{\infty} \Psi(\delta \rho P \Psi)^{t^{\prime}} E\right)_{s_{t}} \psi_{t} \\
& =\left(\Psi(I-\delta \rho P \Psi)^{-1} E\right)_{s_{t}} \psi_{t}
\end{aligned}
$$

which proves (9). The expression for output given in the proposition (see (10)) follows from the above expression for inflation, (5), (8), and $\tilde{\Psi}=\operatorname{diag}(\tilde{\psi})$.

\footnotetext{
${ }^{27}$ Eq. (24) can be derived by using the law of iterated expectations, the relationship $\mathbb{E}\left[\psi_{s_{t+t^{\prime}}} \mid s_{t+t^{\prime}-1}=\sigma\right]=(P \psi)_{\sigma}=(P \operatorname{diag}(\psi) E)_{\sigma}=(P \Psi E)_{\sigma}$, and $\mathbb{E}\left[\psi_{s_{t+1}} \phi_{s_{t+1}} \mid s_{t}=\sigma\right]=$ $(P \operatorname{diag}(\psi) \phi)_{\sigma}=(P \Psi \phi)_{\sigma}$, which holds for arbitrary $S$-dimensional column vectors $\phi$.
} 


\section{B Appendix to Section 5.5}

In this appendix, we derive the transition matrix $P$ and the matrices $\Psi$ and $\tilde{\Psi}$ for the scenario with $N$ committee members. We start with the $(N+1) \times(N+1)$ matrix $P$. With slight abuse of notation, we write $P\left(n, n^{\prime}\right)=P_{n-1, n^{\prime}-1}$ for the probability of the committee comprising $n^{\prime}$ members of type 1 in the next period, conditional on it comprising $n$ members of this type in the current period. Moreover, we introduce $\rho:=1 / 2 \cdot(1+p)$ as the probability of a particular seat on the committee being filled by a member of identical type after one period (notice that this expression can be decomposed into $p$, which is the probability of a member remaining in office, and $1 / 2 \cdot(1-p)$, which is the probability of the member leaving the committee but being replaced by a candidate with identical preferences). After these preliminary steps, the probability of the committee comprising $n^{\prime}$ type-1 members, given that it contained $n$ members of this type in the previous period, can be stated as

$$
P\left(n, n^{\prime}\right)=\sum_{\tilde{n}=\max \left\{0, n^{\prime}+n-N\right\}}^{\min \left\{n^{\prime}, n\right\}}\left(\begin{array}{l}
n \\
\tilde{n}
\end{array}\right) \rho^{\tilde{n}}(1-\rho)^{n-\tilde{n}}\left(\begin{array}{c}
N-n \\
n^{\prime}-\tilde{n}
\end{array}\right)(1-\rho)^{n^{\prime}-\tilde{n}} \rho^{N-n-\left(n^{\prime}-\tilde{n}\right)} .
$$

This expression is somewhat involved but can be interpreted in the following way. The sum is over $\tilde{n}$, which counts the number of experts who were originally of type 1 and who are still of this type one period later. The respective probability is $\left(\begin{array}{l}n \\ \tilde{n}\end{array}\right) \rho^{\tilde{n}}(1-\rho)^{n-\tilde{n}}$. We are only counting constellations, where the new total number of type-1 central bankers is $n^{\prime}$, which means that $n^{\prime}-\tilde{n}$ of the $N-n$ central bankers who were of type 2 in the previous period have changed their types. The respective probability is $\left(\begin{array}{c}N-n \\ n^{\prime}-\tilde{n}\end{array}\right)(1-\rho)^{n^{\prime}-\tilde{n}} \rho^{N-n-\left(n^{\prime}-\tilde{n}\right)}$. Combining these expressions yields $(25)$, which completely characterizes matrix $P$.

Finally, we need to specify $\Psi$ and $\tilde{\Psi}$. For this purpose, we have to take into account that the median voter's weight on output stabilization is $a_{2}$ if $n$, i.e. the number of type- 1 central bankers, is smaller than or equal to $(N+1) / 2$. It is $a_{1}$ otherwise. This gives

$$
\Psi=\operatorname{diag}(\underbrace{\psi_{2}, \psi_{2}, \ldots, \psi_{2}}_{(N+1) / 2 \text { times }}, \underbrace{\psi_{1}, \psi_{1}, \ldots, \psi_{1}}_{(N+1) / 2 \text { times }})
$$


where $\operatorname{again} \operatorname{diag}(v)$ for some vector $v$ is the diagonal matrix with the entries of $v$ on its diagonal. Analogously to $\Psi, \tilde{\Psi}$ is given by

$$
\tilde{\Psi}=\operatorname{diag}(\underbrace{\tilde{\psi}_{2}, \tilde{\psi}_{2}, \ldots, \tilde{\psi}_{2}}_{(N+1) / 2 \text { times }}, \underbrace{\tilde{\psi}_{1}, \tilde{\psi}_{1}, \ldots, \tilde{\psi}_{1}}_{(N+1) / 2 \text { times }})
$$

where we have used the definition of $\tilde{\psi}_{\sigma}$ in equation (8). Equations (26) and (27) can be plugged into (9)-(12) to obtain expressions for output, inflation and their unconditional variances.

\section{Appendix to Section 5.6}

In this appendix, we provide details on how to compute the equilibrium in the scenario where committee members are appointed by the government. As a preliminary step, we specify the set of states $\mathcal{S}=\{1, \ldots, S\}$. The number of states $S$ amounts to $(N+$ 1) $\times 2$, which follows from the observation that there are $(N+1)$ different committee compositions (there may be $0,1, \ldots, N$ central bankers of type 1 ) and two different government types. We introduce the following convention for the labeling of states $\sigma \in \mathcal{S}$. If there are $n(0 \leq n \leq N)$ members of type 1 and the government is of type $\tau \in\{1,2\}$, then the state is

$$
\sigma:=(n+1)+(N+1)(\tau-1) .
$$

Thus we arrange the $(n, \tau)$ 's $(0 \leq n \leq N, \tau \in\{1,2\})$ in the order

$$
(0,1),(1,1),(2,1), \ldots(N, 1),(0,2),(1,2),(2,2), \ldots(N, 2)
$$

To derive $P$, we first compute an auxiliary $(N+1) \times(N+1)$ matrix $\tilde{P}$, which contains the transition probabilities, given the fixed type of government $\tau=1$. In particular, for $n=$ $0, \ldots, N$ and $n^{\prime}=0, \ldots, N, \tilde{P}\left(n, n^{\prime}\right)=\tilde{P}_{n+1, n^{\prime}+1}$ gives the probability of the committee comprising $n^{\prime}$ type- 1 members if there were $n$ type- 1 members in the previous period, conditional on the government being of type 1 . The entries of the auxiliary matrix can be expressed as

$$
\tilde{P}\left(n, n^{\prime}\right)= \begin{cases}\left(\begin{array}{l}
N-n \\
n^{\prime}-n
\end{array}\right)(1-p)^{n^{\prime}-n} p^{N-n^{\prime}} & \text { for } n^{\prime} \geq n \\
0 & \text { for } n^{\prime}<n\end{cases}
$$


We note that $\tilde{P}$ is upper triangular. This observation follows from the fact that the government will fill every vacancy with a candidate sharing its objectives. As a consequence, the number of type-1 central bankers cannot decrease, conditional on the incumbent government being of type 1 .

Example: It is instructive to consider $N=1$ as an example. In this case, we obtain

$$
\tilde{P}=\left(\begin{array}{cc}
p & 1-p \\
0 & 1
\end{array}\right)
$$

The entries are readily interpreted. In the first row, the first entry (p) gives the probability that, given that the single committee member is not of type 1 (and hence of type 2), he will also be of type 2 one period later. This can only occur when this particular central banker remains in office. Otherwise, the government, which is of type 1, will replace the central banker by someone of its own type (this will occur with probability $1-p$, which yields the second entry in the first row). In the second row, the entry "1" can be explained by the observation that a central banker of type 1 will always be replaced by a candidate with the same preferences, given that the government is of type 1 . If the government were fixed for all periods, then the entry "1" would be associated with an absorbing state $n=1$.

Let $\hat{P}$ be $\tilde{P}$, rotated by 180 degrees. Matrix $\hat{P}$ gives the probabilities of transitions from a committee comprising $n$ type- 1 members to one of $n^{\prime}$ type- 1 members conditional on the government being of type $\tau=2$ (rather than type 1 as in the case of $\tilde{P}$ ). Because $\hat{P}$ is the result of a 180 -degrees rotation of the upper triangular matrix $\tilde{P}$, it is lower triangular.

Example (continued): We use the example with $N=1$ to illustrate $\hat{P}$ 's properties:

$$
\hat{P}=\left(\begin{array}{cc}
1 & 0 \\
1-p & p
\end{array}\right)
$$

The interpretation is very similar to the one of $\tilde{P}$. Conditional on the government being of type 2, a central banker who is of type 2 will always be succeeded by a central banker of the same type. This explains the first row, which gives the transition probabilities for an initial central banker of type 2. The second row implies that a central banker of type 1 will remain in office with probability $p$. With the complementary probability, he will resign and be replaced by a candidate of type 2. 
With the auxiliary matrices $\tilde{P}$ and $\hat{P}$, we are now in a position to write $P$ as:

$$
P=\left(\begin{array}{cc}
q \tilde{P} & (1-q) \hat{P} \\
(1-q) \tilde{P} & q \hat{P}
\end{array}\right)
$$

Example (continued): In the example with a one-member committee, the transition matrix $P$ is

$$
P=\left(\begin{array}{cccc}
q p & q(1-p) & 1-q & 0 \\
0 & q & (1-q)(1-p) & (1-q) p \\
(1-q) p & (1-q)(1-p) & q & 0 \\
0 & 1-q & q(1-p) & q p
\end{array}\right)
$$

Consider, e.g., the third entry in the second row, which is $(1-q)(1-p)$. This expression gives the transition probability from $(n=1, \tau=1)$ (the central banker and the government are of type 1) to $\left(n^{\prime}=0, \tau=2\right)$ (the government and the central banker are of type 2). ${ }^{28}$ This transition occurs if the government changes, which happens with probability $1-q$, and the new government immediately has the opportunity to pick a new central banker, which happens with probability $1-p$.

Finally, we note that there are several zero entries in $P$. This is a result of the fact that transitions in which the government in the next period will be of type $\tau$, while at the same time the number of central bankers sharing its preferences will decrease, are impossible. This follows from the observation that each government fills all vacancies with central bankers sharing its objectives.

However, it is always possible to reach every state $\sigma^{\prime} \in \mathcal{S}$ from all states $\sigma \in \mathcal{S}$ in two steps, as can be verified formally by computing $P^{2} \cdot{ }^{29}$ This fact is crucial as it guarantees the existence of a unique stationary distribution. Moreover, it ensures that this distribution is reached asymptotically irrespective of the starting distribution.

\footnotetext{
${ }^{28}$ Recall that $n$ and $n^{\prime}$ give the numbers of type- 1 central bankers in a particular period and a consecutive period respectively. This entails, in particular, that the central banker is of type 2 when the number of type- 1 central bankers is zero $\left(n^{\prime}=0\right)$.

${ }^{29}$ To see that all entries in $P^{2}$ are strictly positive, one can compute $P^{2}$ by using (29). The claim then immediately follows from the facts that $\tilde{P}$ is upper triangular with all entries in the upper-right part (including the diagonal entries) strictly positive and that $\hat{P}$ is lower triangular with all entries in the lower-left part (again including the diagonal) strictly positive.
} 


\section{Optimal Delegation}

Using (5) to eliminate $y_{t}$, we can restate the optimization problem in (21) as

$a_{1}\left(a_{2}\right)=\operatorname{argmax}_{a_{1}}\left\{\left(\sum_{\tau=0}^{\infty} \delta^{\tau} P^{\tau} \rho^{\tau}\left(W \circ\left(\Psi(I-\delta \rho P \Psi)^{-1} E\right) \circ\left(\Psi(I-\delta \rho P \Psi)^{-1} E\right)\right)\right)_{\sigma=1}\right\}$

subject to (7), (8), (20), $W=\left(1+b \lambda^{2} / a_{1}^{2}, 1+b \lambda^{2} / a_{2}^{2}\right)^{T}$, and $a_{2}$ given.

The circle "○" denotes the Hadamard product, i.e. component-wise multiplication. With the help of $\sum_{\tau=0}^{\infty} \delta^{\tau} P^{\tau} \rho^{\tau}=(I-\delta P \rho)^{-1}$, the first-order condition can be stated as

$$
\frac{d}{d a_{1}}\left((I-\delta P \rho)^{-1}\left(W \circ\left(\Psi(I-\delta \rho P \Psi)^{-1} E\right) \circ\left(\Psi(I-\delta \rho P \Psi)^{-1} E\right)\right)\right)_{\sigma=1}=0
$$

To determine the fixed point $a_{1}\left(a_{2}\right)=a_{2}$, one has to set $a^{*}=a_{1}=a_{2}$ in the first-order condition and to solve for $a^{*}$. It is tedious but straightforward to verify that this gives the following simple expression:

$$
a^{*}=(1-\rho \theta \delta) b
$$




\section{References}

Alberto Alesina. Macroeconomic policy in a two-party system as a repeated game. The Quarterly Journal of Economics, 102(3):651-678, August 1987.

David Backus and John Driffill. The consistency of optimal policy in stochastic rational expectations models. CEPR Discussion Papers 124, August 1986.

Roel M. W. J. Beetsma and Henrik Jensen. Inflation targets and contracts with uncertain central banker preferences. Journal of Money, Credit, and Banking, 30(3): 384-403, August 1998.

Aleksander Berentsen and Carlo Strub. Central bank design with heterogeneous agents. European Economic Review, 53(2):139 - 152, February 2009.

Alan S. Blinder. Monetary policy by committee: Why and how? European Journal of Political Economy, 23(1):106-123, March 2007.

Alan S. Blinder and John Morgan. Are two heads better than one? Monetary policy by committee. Journal of Money, Credit and Banking, 37(5):789-811, October 2005.

James Bullard and Christopher J. Waller. Central bank design in general equilibrium. Journal of Money, Credit, and Banking, 36(1):95-113, February 2004.

John M. Carey, Richard G. Niemi, and Lynda W. Powell. Term Limits in State Legislatures. University of Michigan Press, 2000.

Stephen G. Cecchetti and Stefan Krause. Central bank structure, policy efficiency, and macroeconomic performance: Exploring empirical relationships. Federal Reserve Bank of St. Louis Review, July 2002.

Richard Clarida, Jordi Galí, and Mark Gertler. The science of monetary policy: A New Keynesian perspective. Journal of Economic Literature, 37(2):1661-1707, December 1999.

Richard Clarida, Jordi Galí, and Mark Gertler. Monetary policy rules and macroeconomic stability: Evidence and some theory. Quarterly Journal of Economics, 115 (1):147-180, 2000. 
M. J. A. N. de Caritat Condorcet. An essay on the application of analysis to the probability of decisions rendered by a plurality of votes. In Iain McLean and Arnold B. Urken, editors, Classics of Social Choice. Ann Arbor: University of Michigan Press, $1995,1785$.

Gary W. Cox and Jonathan N. Katz. Why did incumbency advantage in U.S. House elections grow? American Journal of Political Science, 40(2):478-497, May 1996.

Robert S. Erikson. The advantage of incumbency in congressional elections. Polity, 3 (3):395-405, Spring 1971.

Marcela Eslava. Central bankers in government appointed committees. Journal of Public Economics, 94(56):363-379, June 2010.

Etienne Farvaque, Norimichi Matsueda, and Pierre-Guillaume Méon. How monetary policy committees impact the volatility of policy rates. Journal of Macroeconomics, $31(4): 534-546,2009$.

Petra Gerlach-Kristen. Monetary policy committees and interest rate setting. European Economic Review, 50(2):487-507, February 2006.

Kerstin Gerling, Hans Peter Grüner, Alexandra Kiel, and Elisabeth Schulte. Information acquisition and decision making in committees: A survey. European Journal of Political Economy, 21(3):563-597, September 2005.

Hans Gersbach and Volker Hahn. Voting transparency in a monetary union. Journal of Money, Credit, and Banking, 41(5):809-830, August 2009.

Hans Gersbach and Volker Hahn. Information acquisition and transparency in committees. International Journal of Game Theory, 41(2):427-453, July 2011.

Volker Hahn. Transparency of central bank preferences. German Economic Review, 10 (1):32-49, 2009.

Lars Ljungqvist and Thomas J. Sargent. Recursive Macroeconomic Theory. Cambridge, MA: MIT Press, 2nd edition, 2004. 
C. Duncan MacRae. A political model of the business cycle. Journal of Political Economy, 85(2):239-263, April 1977.

Bennett T. McCallum. Two fallacies concerning Central-Bank independence. American Economic Review, 85(2):207-211, May 1995.

Ellen E. Meade and D. Nathan Sheets. Regional influences on FOMC voting patterns. Journal of Money, Credit, and Banking, 37(4):661-667, August 2005.

Ilian Mihov and Anne Sibert. Credibility and flexibility with independent monetary policy committees. Journal of Money, Credit, and Banking, 38(1):23-46, February 2006.

Carlos Montoro. Monetary policy committees and interest rate smoothing. CEP discussion paper, Centre for Economic Performance, LSE, 2007.

William D. Nordhaus. The political business cycle. Review of Economic Studies, 42 (2):169-190, April 1975.

Gilles Oudiz and Jeffrey D. Sachs. International policy coordination in dynamic macroeconomic models. NBER Working Paper 1417, August 1984.

William Poole. After Greenspan: Whither Fed policy? speech given at the Western Economics Association International Conference, San Francisco, California, July 6, 2005,2005 .

Alessandro Riboni. Committees as substitutes for commitment. International Economic Review, 51(1):213-236, February 2010.

Alessandro Riboni and Francisco Ruge-Murcia. The dynamic (in)efficiency of monetary policy by committee. Journal of Money, Credit, and Banking, 40(5):1001-1032, August 2008.

Alessandro Riboni and Francisco J. Ruge-Murcia. Preference heterogeneity in monetary policy committees. International Journal of Central Banking, 4(1):213-233, March 2008. 
Alessandro Riboni and Francisco J. Ruge-Murcia. Monetary policy by committee: Consensus, chairman dominance, or simple majority? The Quarterly Journal of Economics, 125(1):363-416, February 2010.

Kenneth Rogoff and Anne Sibert. Elections and macroeconomic policy cycles. The Review of Economic Studies, 55(1):1-16, January 1988.

Anne Sibert. Monetary policy with uncertain central bank preferences. European Economic Review, 46(6):1093-1109, June 2002.

Anne Sibert. Monetary policy committees: Individual and collective reputation. Review of Economic Studies, 70(3):649-665, July 2003.

Anne Sibert. Central banking by committee. International Finance, 9(2):145-168, August 2006.

Jan Rose Sørensen. Political uncertainty and macroeconomic performance. Economics Letters, 37(4):377-381, December 1991.

Geoffrey M.B Tootell. Whose monetary policy is it anyway? Journal of Monetary Economics, 43(1):217-235, February 1999.

Christopher J. Waller. Monetary policy games and central bank politics. Journal of Money, Credit, and Banking, 21(4):422-431, November 1989.

Christopher J. Waller. Policy boards and policy smoothing. Quarterly Journal of Economics, 115(1):305-339, February 2000.

Christopher J. Waller and Carl E. Walsh. Central-bank independence, economic behavior, and optimal term lengths. American Economic Review, 86(5):1139-1153, December 1996.

Michael Woodford. Interest and Prices: Foundations of a Theory of Monetary Policy. Princeton University Press, Princeton, New Jersey, 2003. 